\title{
Recombinant Thermostable AP Exonuclease from Thermoanaerobacter tengcongensis: Cloning, Expression, Purification, Properties and PCR Application
}

\author{
SŁAWOMIR DĄBROWSKI ${ }^{1 *}$, ANNA BRILLOWSKA-DABROWSKA² and BIRGITTE K. AHRING \\ ${ }^{1}$ The Environmental Microbiology \& Biotechnology Research Group, BioCentrum, Søltofts Plads, \\ Building 227, Technical University of Denmark, DK-2800 Kgs. Lyngby, Denmark \\ ${ }^{2}$ Department of Microbiology, Gdańsk University of Technology
}

Received 10 July 2012, revised 26 February 2013, accepted 12 March 2013

Abstract

\begin{abstract}
Apurinic/apyrimidinic (AP) sites in DNA are considered to be highly mutagenic and must be corrected to preserve genetic integrity, especially at high temperatures. The gene encoding a homologue of AP exonuclease was cloned from the thermophilic anaerobic bacterium Thermoanaerobacter tengcongensis and transformed into Escherichia coli. The protein product showed high identity (80\%) to human Ape1 nuclease, whereas to E. coli exonuclease III - 78\%. This is the first prokaryotic AP nuclease that exhibits such high identity to human Ape1 nuclease. The very high expression level (57\% of total soluble proteins) of fully active and soluble His -tagged Tte AP enzyme with His $_{6}$-tag on C-terminal end was obtained in Escherichia coli Rosetta (DE3) pLysS. The active enzyme was purified up to $98 \%$ homogeneity in one chromatographic step using metal-affinity chromatography on $\mathrm{Ni}^{2+}$-IDA-Sepharose resin. The yield was $90 \mathrm{mg}(14000 \mathrm{kU})$ of pure His $_{6}$-tagged Tte AP (153 kU/mg) from 1 liter of culture. The optimal conditions of Tte AP endo-, exonuclease and 3'-nuclease activity were investigated using fluorescein labeled dsDNA with inserted AP sites and ssDNA. Optimal Tte AP endonuclease activity was observed at $70-75^{\circ} \mathrm{C}, \mathrm{pH} 8.0$ and at low $\mathrm{Mg}^{2+}$ concentration $(0.5 \mathrm{mM})$. Higher $\mathrm{Mg}^{2+}$ concentration $(>1 \mathrm{mM})$ enhanced $3^{\prime}-5^{\prime}$ exonuclease activity and at $\mathrm{Mg}^{2+}$ concentration $>2.0 \mathrm{mM}$ 3' nuclease activity was observed.Because of the endonuclease activity of Tte AP exonuclease, the enzyme was applied in PCR amplification of long DNA templates. Tte AP exonuclease eliminated AP-sites in DNA template and improved the efficiency of DNA amplification.
\end{abstract}

Ke y words: AP endonuclease, AP site, DNA damage, Polymerase Chain Reaction Thermoanaerobacter tengcongensis

\section{Introduction}

Repair of DNA damages by base excision is one of the main strategies used by the cell to defend against exogenous or endogenous genotoxic stress. These damages have the potential to cause cell death or mutation. All organisms possess a panel of DNA repair mechanisms to repair damaged DNA and to maintain viability and genomic stability. Among these DNA repair mechanisms, base excision repair (BER) is one of the most highly conserved. Enzymes of the BER pathway act to remove the abasic fragment, fill the nucleotide gap, and seal the nick. AP endonucleases from Escherichia coli are classified into two main families termed exonuclease III (ExoIII or Xth) and endonuclease IV (EndoIV or Nfo).

The ExoIII protein of E.coli is a 3'-phosphatase capable of activating DNA substrates for polymerase- mediated primer extension (Richardson and Kornberg, 1964), and has AP endonuclease, 3' -5' exonuclease and RNase H activity (Demple and Harrison, 1994; Wilson et al., 1998). The 3'-phospohodiesterase and AP endonuclease activities of ExoIII play a major role in the BER pathway. Interestingly, Neisseria meningitidis posseses two AP endonucleases that have distinct activities in DNA repair: one is a typical Neisserial AP endonuclease (NApe), whereas the other is a specialised 3'-phosphodiesterase Neisserial exonuclease (NExo) (Carpeneter et al. 2007).

The human major abasic endonuclease is Ape1, an ExoIII homologue (Wilson and Barsky, 2001). Unlike ExoIII, the human enzyme has relatively poor 3'-5' exonuclease activity (Lebedeva et al., 2003), but exhibits AP endonuclease activity (Seki et al., 1992; Wilson et al., 1995) as well as very selective 3'-phosphodiesterase activity (Suh et al., 1997). Apel was found to be the

* Corresponding author: Sławomir Dąbrowski, The Environmental Microbiology \& Biotechnology Research Group, BioCentrum, Søltofts Plads, Building 227, Technical University of Denmark, DK-2800 Kgs. Lyngby, Denmark; phone: +48 587351182; e-mail: slawekdabrowski@yahoo.com 
major 3'-nuclease that can excise analogs of nucleotides (Chou et al., 2000). The nuclease specificity of Ape1 and Ape2 was recently investigated (Hadi et al., 2002). It was found that mutation at F226 and W280 of Ape1 increases 3'-5' exonuclease activity. Recently discovered yeast Eth1/Apn 2 and human Ape2 proteins (Bennett, 1999; Hadi and Wilson, 2000; Johnson et al., 1998; Unk et al., 2000) exhibit high similarity within the core of nuclease domains of Ape1 and ExoIII, but show relatively poor AP endonuclease and 3'-repair activities (Bennett, 1999; Hadi and Wilson, 2000; Unk et al., 2000; Unk et al., 2001).

The thermophilic AP endonuclease from the archeon Archaeoglobus fulgidus was described by Schmiedel et al. The enzyme shared 33\% overall sequence identity and 55\% similarity to ExoIII. It showed a strong $\mathrm{Mg}^{2+}$ dependent nicking activity at AP-sites, nicking of undamaged double-stranded (ds) DNA and a weak exonucleolytic activity (Schmiedel et al., 2009).

Thermoanaerobacter tengcongensis isolated from Chinese hot spring, a rod-shaped, Gram-negative, anaerobic bacterium that was recently described as an extremely thermophilic bacterium (Xue et al., 2001). The complete genome sequence of $T$. tengcongensis clone MB4T (Bao et al., 2002) consists of a 37.6\% GC-content $2,689,441$, base pair (bp) circular chromosome that contains 2808 predicted coding regions, 1,481 (52.7\%), which have functional assignments, and 1,327 (47.3\%) of which are of unknown function. Genome analysis also reveals that 30 genes have their homologues in the genomes of other thermophilic eubacteria and archaea.

The results of this study demonstrates that Tte AP exonuclease from Thermoanaerobacter tengcongensis exhibits high similarity to human Apel enzyme and exhibits 3'-nuclease activity. The Tte AP exonuclease can be efficiently produced in E. coli over-expression system and large amount of fully active protein can be purified using a single-step chromatography procedure with $\mathrm{Ni}^{2+}$-IDA-sepharose. We also report the application of the recombinant Tte AP exonuclease in PCR analysis.

\section{Experimental}

\section{Materials and Methods}

Bacterial strains, plasmids, enzymes, and reagents. Thermoanaerobacter tengcongensis (DSM 15242) was purchased from Deutsche Sammlung von Mikroorganismen und Zellkulturen GmbH. E. coli TOP10F, pUC57, were used for cloning of gene for Tte AP exonuclease. The Rosetta(DE3)pLysS strain and pET-30 LIC plasmid were applied for expression of $\mathrm{His}_{6}$-tagged Tte AP exonuclease. $\mathrm{Ni}^{2+}$-IDA-sepharose $6 \mathrm{~B}$ was prepared as described by Porath etal. (Porath and Olin,
1985). Restriction and modification enzymes were purchased from NEB (USA) and Fermentas MBI (Lithuania). The reagents for PCR, IPTG, agarose and reagents for protein purification were purchased from Sigma (USA), oligonucletides were purchased from MWG Biotech (Germany).

Phylogenic analysis of AP-sites excision enzymes. Based on the T. tengcongensis genomic DNA sequence (GenBank acc. No. NC003869) of the gene encoding potential AP endonuclease (ExoIII) was found (locus TTE2226) and translated into amino acid sequence The comparison with other known eukaryotic and prokaryotic AP-sites excision enzymes was performed using program AlignX from Vector NTI Suite 7.1 software package (Invitrogen, Inc.). The phylogenic tree was constructed using the same program regarding to Kimura's correction and the phylogenetic tree was built using the Neighbour Joining method (NJ) of Saitou and Nei.

Cloning of the gene encoding Tte AP exonuclease from T. tengcongensis. Genomic DNA from Thermoanaerobacter tengcongensis was isolated using Genomic DNA Prep Kit (A\&A Biotechnology, Poland). The specific primers were designed: TteAPE1Nde, (5' GCGGCGCATATGAAACTCGTATCGTGG 3') (containing NdeI recognition site), TteAPE1-XhoC-His (5'GCGGCGCTCGAGTTTTATGAGGTCTTCTTTTAC-

TATAAG 3') (containing XhoI recognition site). The bolded parts of primer sequences are complementary to the nucleotide sequences of the gene encoding Tte AP exonuclease, whereas 5 ' overhanging ends of primers contain recognition sites for restriction endonucleases (underlined), and are designated to facilitate cloning. The reaction solution consisted of: $50 \mathrm{ng}$ of the T. tengcongensis genomic DNA, $2 \mu \mathrm{l}(10 \mu \mathrm{M})$ of each primer, $5 \mu \mathrm{l}(10 \mathrm{mM}) \mathrm{dNTPs}, 5 \mu \mathrm{l} 10 \times$ PCR buffer $(100 \mathrm{mM}$ Tris-HCl, pH 8.9, $500 \mathrm{mM} \mathrm{KCl}, 25 \mathrm{mM} \mathrm{MgCl}_{2}, 1 \%$ Triton X-100), $2 \mathrm{U}$ of $P$ wo DNA polymerase (Dabrowski and Kur, 1998) and 30 cycles were performed with a temperature profile of $30 \mathrm{~s}$ at $94^{\circ} \mathrm{C}, 1 \mathrm{~min}$ at $55^{\circ} \mathrm{C}$, and $1 \mathrm{~min}$ at $72^{\circ} \mathrm{C}$. The amplified product was analyzed by electrophoresis on a $1 \%$ agarose gels stained with ethidium bromide. Specific PCR product was obtained (approximately $802 \mathrm{bp} ; 0.1 \mu \mathrm{g}$ ) and purified using Clean-Up Kit (A\&A Biotechnology, Poland). The product was then phosphorylated using T4 polynucleotide kinase and then ligated with pUC57/SmaI dephosphorylated plasmid vector. The E. coli TOP10F' cells were transformed with the ligation mixture and colonies were assayed for the presence of the gene encoding Tte AP exonuclease by PCR amplification and restriction analysis. DNA fragments encoding Tte AP exonuclease gene were excised using NdeI and XhoI endonucleases and cloned into pET-30 LIC expression plasmid in NdeI and XhoI sites. After E. coli TOP10F' transformation, four clones were selected and sequenced. After 
sequencing, one of the plasmids (pET30TteAPC) was chosen and used for $\mathrm{His}_{6}$-tagged Tte AP exonuclease expression and purification procedure.

Purification of the Tte AP exonuclease. Rosetta (DE3)pLysS strain transformed with pET30TteAPC plasmid was grown overnight at $37^{\circ} \mathrm{C}$ in $10 \mathrm{ml} \mathrm{LB}$ supplemented with $50 \mu \mathrm{g} / \mathrm{ml}$ chloramphenicol and $34 \mu \mathrm{g} / \mathrm{ml}$ kanamycin and $0.5 \%$ glucose. After $24 \mathrm{~h}, 500 \mathrm{ml} \mathrm{LB}$ containing $50 \mu \mathrm{g} / \mathrm{ml}$ chloramphenicol and $34 \mu \mathrm{g} / \mathrm{ml}$ kanamycin was inoculated and the culture was followed to an O.D. of 0.3 at $600 \mathrm{~nm}$. IPTG was then added to the final concentration of $0.5 \mathrm{mM}$, and then culture was continued until cells reach the stationary phase. The cells were harvested by centrifugation and the pellet was resuspended in $10 \mathrm{ml}$ of buffer A ( $20 \mathrm{mM}$ Tris- $\mathrm{HCl}$, $\mathrm{pH} 7.5,500 \mathrm{mM} \mathrm{NaCl}, 5 \mathrm{mM}$ imidazole, $0.1 \%$ Triton $\mathrm{X}-100$ ). Cells were disrupted by fast freezing at $-80^{\circ} \mathrm{C}$, and then were homogenized for $5 \mathrm{~min}$, and insoluble proteins were removed by centrifugation. The clarified supernatant was further applied directly onto a $\mathrm{Ni}^{2+}$ IDA-sepharose $6 \mathrm{~B}$ column ( $10 \mathrm{ml}$ of bed volume) preequilibrated with buffer $A$. The column was washed preliminary with $30 \mathrm{ml}$ buffer $\mathrm{A}$, and with $30 \mathrm{ml}$ of buffer A containing $50 \mathrm{mM}$ imidazole, and washed again with buffer A containing $80 \mathrm{mM}$. The Tte AP exonuclease was eluted using buffer A containing $0.5 \mathrm{M}$ imidazole. The purity of the eluted protein was over $98 \%$. Pure Tte AP exonuclease was dialyzed against storage buffer AG (20 mM Tris- $\mathrm{HCl} \mathrm{pH}$ 8.0, $50 \mathrm{mM} \mathrm{KCl,} \mathrm{50 \%} \mathrm{glycerol)}$ with PMSF (phenylmethylsulfonyl fluoride) and stored at $-20^{\circ} \mathrm{C}$ until use.

Tte AP exonuclease activity assays. For the analysis of properties of Tte AP exonuclease, a different 5 ' fluorescein labeled dsDNA and ssDNA were used. The AP endonuclease activity was assayed using $50 \mathrm{nt}$ hybrid DNA combined from two synthetic oligonucleotides with inserted AP sites (AP-fluoro: Fluorescein-5' GCATAGACATAGATACAGATACAT ${ }^{\text {AP }}$ CTAGAGACTAGGCTCGTAATCCCA G 3' and AP: 5'CTGGGATTACGAGCCTAGTCTC ${ }^{A P} A G G A T G T A T C T-$ GTATCTATGTCTATGC 3'). The 3'-5' exonuclease activity of Tte AP exonuclease was examined using a dsDNA hybrid consisted of three synthetic oligonucleotides forming nicked DNA (FluoroHyb1: Fluorescein-5' GCGGCGGCTGGCACC 3', Hyb 2: GCTGGCTCGGGTGGGCCTGAGCTGCCTGGCGGCAC 3' and Hyb3 5'GTGCCGCCAGGCAGCTCAGGCCCACCCGAGCCAGCGGTGCCAGGCGCCGC 3'). The 3'-5' exonuclease activity was also investigated using hybrid DNA combined from Hyb1 and Hyb3 oligonucleotides. The 3'-nuclease activity was analyzed using FluoroHyb1 oligonucleotide. All reactions were performed at $70^{\circ} \mathrm{C}$ for $30 \mathrm{~min}$ at $66 \mathrm{mM}$ Tris- $\mathrm{HCl}$ (pH 8.0) buffer - 20 pmol of DNA and $100 \mathrm{U}$ of Tte AP exonuclease were used. The thermostability of Tte AP exonuclease was evaluated at different temperatures (from $37^{\circ} \mathrm{C}$ up to $95^{\circ} \mathrm{C}$ ) using $10 \mathrm{pmol}$ of AP-DNA and $200 \mathrm{U}$ of enzyme and incubated for $15 \mathrm{~min}$ in $66 \mathrm{mM}$ Tris- $\mathrm{HCl}$ ( $\mathrm{pH}$ 8.0) buffer containing $0.5 \mathrm{mM} \mathrm{Mg}^{2+}$.

Use of Tte AP exonuclease in PCR analysis. Different amounts of the E. coli genomic DNA (300 to $0.1 \mathrm{ng}$ ) were depurinated by heating in $0.01 \mathrm{M}$ sodium citrate buffer $\mathrm{pH} 5.1,0.1 \mathrm{NaCl}$ at $75^{\circ} \mathrm{C}$ for $60 \mathrm{~min}$. Depurinated DNA samples were incubated in $66 \mathrm{mM}$ Tris $\mathrm{pH} 8.0$, $0.5 \mathrm{mM} \mathrm{MgCl}_{2}$ with $30 \mathrm{U}$ of Tte AP exonuclease was incubated at $70^{\circ} \mathrm{C}$ for $30 \mathrm{~min}$, then the enzyme was denatured at $90^{\circ} \mathrm{C}$ for $5 \mathrm{~min}$. Enzyme treated DNA samples were amplified. The length of DNA target was approximately $3000 \mathrm{bp}$. The PCR was carried out with cloned Pwo DNA polymerase $2.5 \mathrm{U} / 50 \mu \mathrm{l}$ of reaction combined with Pwo dUTPase (Dabrowski and Ahring, 2003). PCR was performed using primer Sup (5’ AGGCCTGATAAGCGCAGCGTATCAGG 3') and primer Fr3 (5'CCGATATGTGCGAAGGCTTACCGG $3^{\prime}$ ) and 30 cycles with a temperature profile of $30 \mathrm{~s}$ at $94^{\circ} \mathrm{C}, 1 \mathrm{~min}$ at $65^{\circ} \mathrm{C}$, and $3 \mathrm{~min}$ at $72^{\circ} \mathrm{C}$. The presence of the PCR products was analyzed on $1 \%$ agarose gel.

\section{Results and Discussion}

Amino acid sequence analysis of Tte AP exonuclease. The amino acid sequence of Tte AP exonuclease was compared with other BER enzymes using the AlignX program of Vector NTI suite 7 (Invitrogen). Multiple sequence alignment was performed and the phylogenetic tree of Tte AP exonuclease is shown in Fig. 1a. The comparison indicates that group of ExoIII proteins from Clostridiaceae including T. tengcongensis AP exonuclease shows higher identity to eukaryotic AP exonucleases (human, rat, mouse, fruit fly), than to prokaryotic ExoIII proteins. Tte AP exonuclease is similar to human APE1 in $80 \%$ whereas E. coli ExoIII is similar to human APE1 in 78\%. As it was described previously (Hadi et al., 2002), the comparison shows high conservation of these enzyme sequences. The high similarity between enzymes from the BER pathways is probably the consequence of their important function in DNA damage repair. Focused on E. coli ExoIII, Tte AP exonuclease and human APE1 proteins alignment is separately presented in Fig. 1b. The high similarity of Tte AP exonuclease to human Apel protein is clearly shown. This similarity is within the critical limits for AP site binding or catalysis where E. coli ExoIII contains different residue (Q112, L226). The analysis of predicted secondary structure also presents higher similarity of Tte AP exonuclease to Ape1 than E.coli ExoIII to APE1 protein. Highly inhibited AP endonuclease function was found in APE1 protein after substitution of residues F226A and W280I (Hadi et al., 2002). 
A

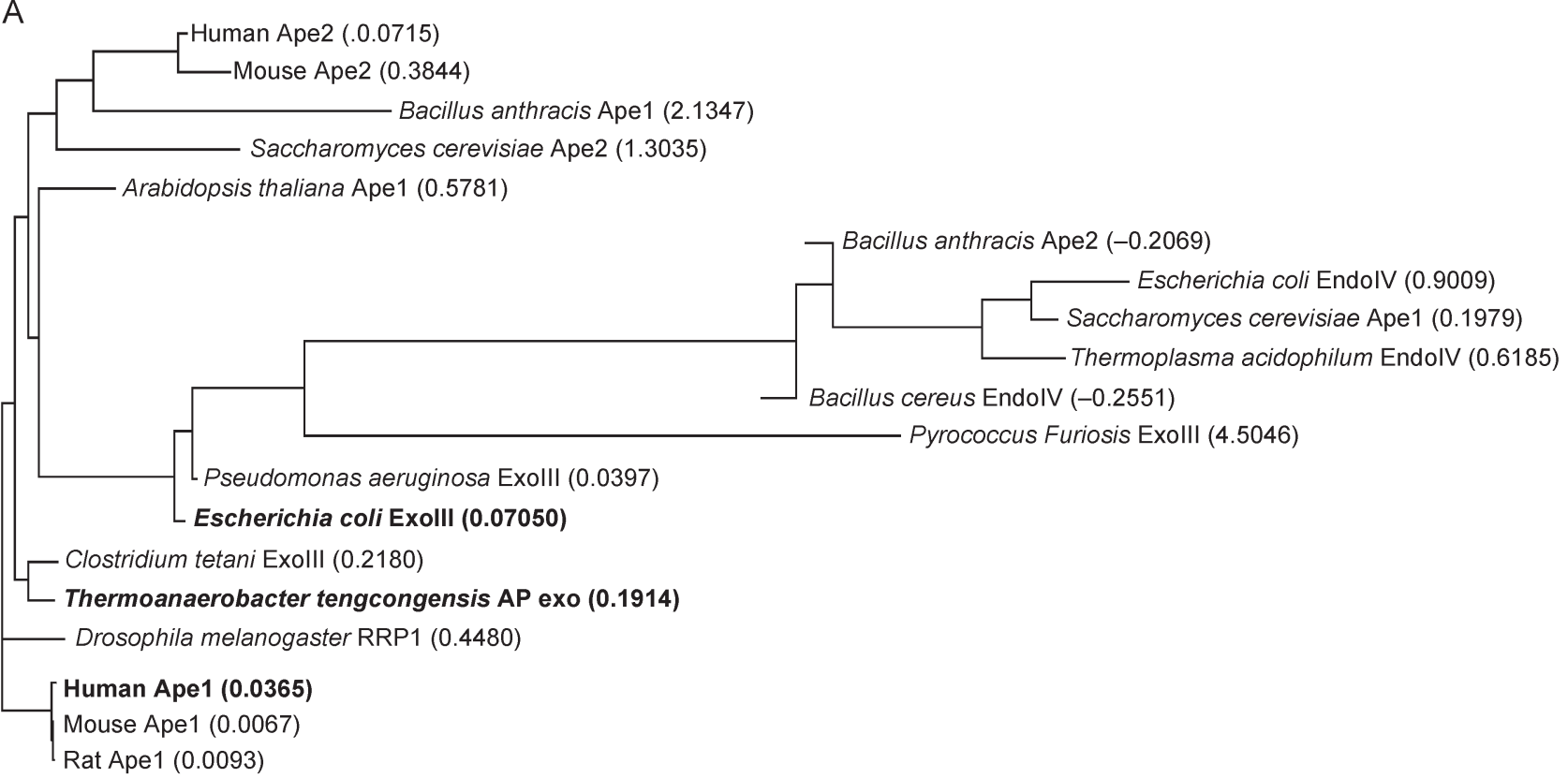

B

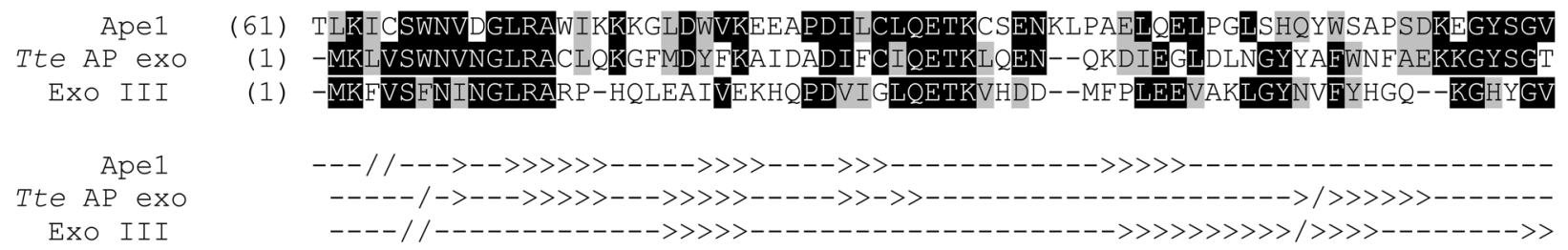

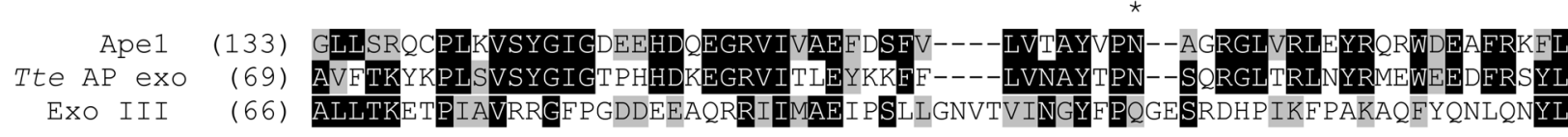
Apel
Tte AP exo
Exo III

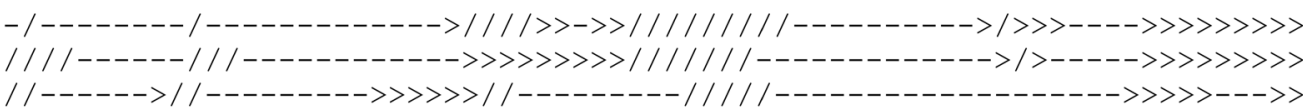
$\begin{array}{ccl}\text { Ape1 } & (198) & \text { KGLASRK-PLVLCGDLNVAHEEIDLRNPKGNKK-----NAGFTPQERQGFGELLQAVPTADSFRHLYPNT } \\ \text { Tte AP exo } & (134) & \text { LKLDSVK-PVILCGDLNVAHQEIDIKNPAANRR-----NAGFTDEERE-KMTILLNSGFIDTFRYYYDK } \\ \text { Exo III } & (137) & \text { ETELKRDNPVLIMGDMNISPTDLDIGIGEENRKRWLRTGKCSELPEERE-WMDRLMSWGIVDTFRHANEQT }\end{array}$

Ape 1
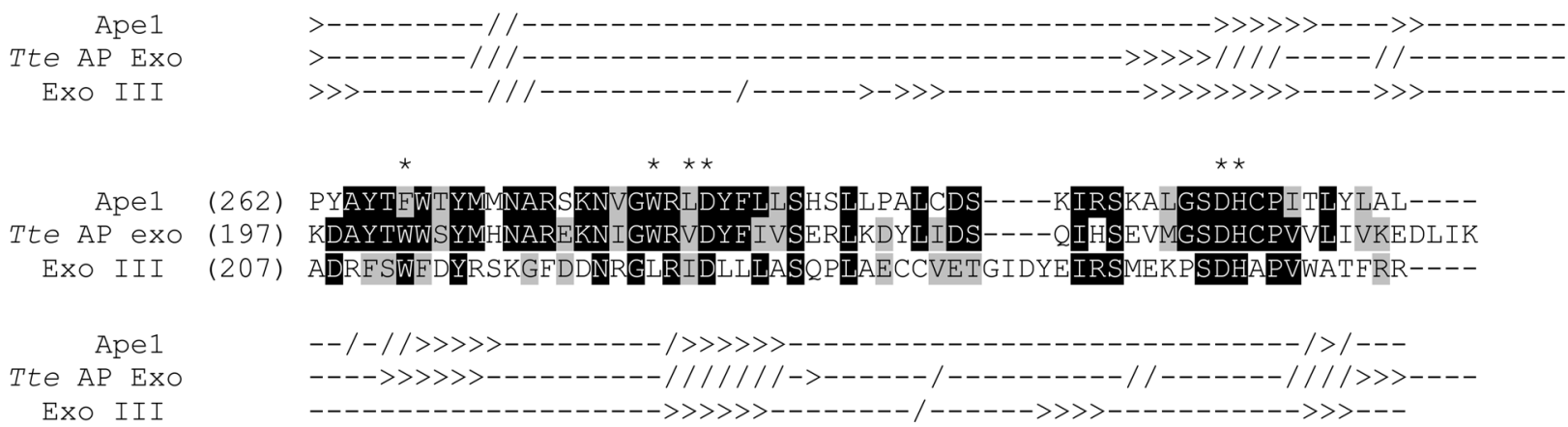

Fig. 1. The amino acid sequence alignment of the BER pathway enzymes. (A) Phylogenic tree of the ExoIII family from different organisms. The calculated distance values in parenthesis is followed the molecule name displayed on the tree. (B) Alignment of the AP endonuclease domains of Ape1, Tte AP exonuclease and ExoIII. Residues conserved in two or more of sequences are highlighted in black (identical) or grey (similar). Residues of Ape1 that are critical for AP site binding of catalysis are indicated by an asterisk $\left(^{*}\right)$. Location of secondary structure elements in Ape1, Tte AP exonuclease and ExoIII (as assessed by NNPREDICT (Kneller et al., 1990; McClelland and Rumelhart, 1988)) are marked below the respective sequences: $\beta$-strands are represented as ' $/$ ', and $\alpha$-helices as '>'. 
The inhibition of E. coli ExoIII binding to AP site was observed when substitution W212S was carried out (Shida et al., 1999). Based on these previous observations, the presence of aromatic residue of Tte AP exonuclease (W202) is required for efficient recognition of AP sites by ExoIII family.

Expression of the recombinant $\mathrm{His}_{6}$-Tagged Tte AP exonucleas. The recombinant His6-Tte Ap exonuclease was produced in E. coli Rosetta(DE3)pLysS harbouring pET30TteAPC plasmid. The host for protein expression contains a modified pLysS plasmid (pRARE) with rarely used tRNA genes in E. coli and gene encoding T7 lysozyme, which strongly represses protein expression by T7 RNA polymerase binding and inhibition. Owing to a high copy in the E. coli cell of this plasmid the multiplication of tRNA is possible and helps to avoid the codon bias of E. coli and enhance the expression of heterologous proteins (Brinkmann et al., 1989; Novy et al., 2001; Seidel et al., 1992). The selected clones were grown in LB medium supplemented with chloramphenicol, kanamycin and glucose. Glucose strongly inhibits protein expression from $\mathrm{pET}$ vector (Fig. 2, lane 3) in E. coli cells and keeps stable number of plasmid copies in the cell during the overnight growth. The induction of Tte AP exonuclease expression was initialized by IPTG addition at $\mathrm{A}_{600}$ of 0.3 and culture was grown for $6 \mathrm{~h}$ at $37^{\circ} \mathrm{C}$ reaching the highest protein expression level (Fig. 2, lane 4).

Purification of the recombinant Tte AP exonuclease. The purity of enzyme was examined by SDS-PAGE (Fig. 2). Soluble $\mathrm{His}_{6}$-tagged Tte AP exonuclease was

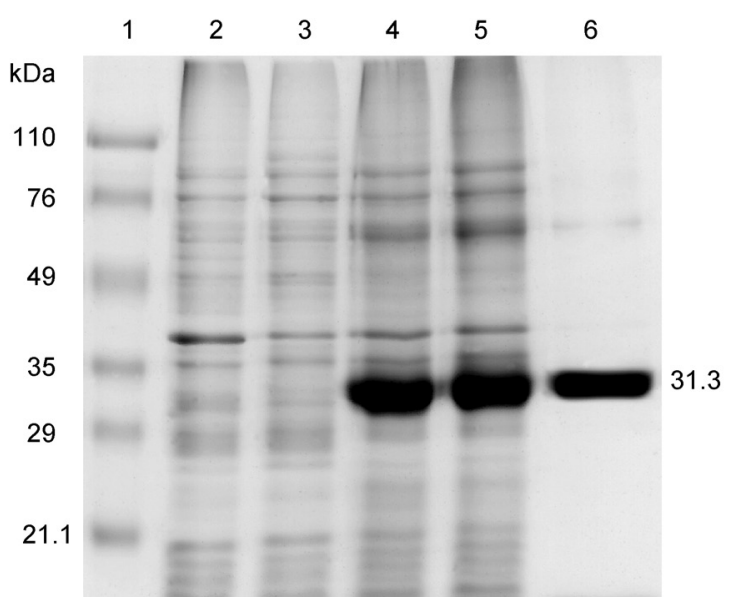

Fig. 2. SDS electrophoresis in $12 \%$ polyacrylamide gel of the fractions obtained by purification of recombinant Tte AP exonuclease from E. coli Rosetta(DE3)pLysS+ pET30TteAPC. Each loaded sample corresponds to $25 \mu \mathrm{l}$ of culture. Lane 1, low molecular weight marker (Bio-Rad); lane 2, lysate from E.coli Rosetta(DE3)pLysS; lanes 3, lysate from E. coli Rosetta(DE3) pLysS+ pET30TteAPC after overnight culture supplemented with $0.5 \%$ of glucose; lanes 4 , lysate after induced expression of Tte AP exonuclease; lanes 5 , fraction of soluble proteins after expression of Tte AP exonuclease; lane 6, Tte AP exonuclease after purification on $\mathrm{Ni}^{2+}$-IDA-sepharose.
Table I

Purification of Tte AP exonuclease from Rosetta(DE3)pLysS strains containing pET30TteAPC plasmid from $500 \mathrm{ml}$ of culture.

\begin{tabular}{|l|c|c|c|c|}
\hline Purification step & $\begin{array}{c}\text { Protein } \\
{[\mathrm{mg}]}\end{array}$ & $\begin{array}{c}\text { Activity of AP } \\
\text { exonuclease } \\
{[\mathrm{kU}]}\end{array}$ & $\begin{array}{c}\text { Specific } \\
\text { activity } \\
{[\mathrm{kU} / \mathrm{mg}]}\end{array}$ & $\begin{array}{c}\text { Expression } \\
\text { level }^{\mathrm{a}} \\
{[\%]}\end{array}$ \\
\hline $\begin{array}{l}\text { Fraction of soluble } \\
\text { proteins }\end{array}$ & 78 & nd & nd & nd \\
\hline $\begin{array}{l}\text { Metal-affinity } \\
\text { chromatography }\end{array}$ & 45 & 7000 & 153 & 56 \\
\hline
\end{tabular}

a Percentage of Tte AP exonuclease protein after purification in relation to total soluble proteins; nd - not determined

expressed in the cytosol (Fig. 2, lane 5). The recombinant enzyme was eluted from the column as a single peak ( 98\% purity) (Fig. 2, lane 6). Another band corresponding to $32 \mathrm{kDa}$ was observed in SDS-PAGE of crude extract of E. coli Rosetta(DE3)pLysS with pET30 TteAP cultures after IPTG induction (Fig. 2, lane 4). This band was absent in the control crude extracts of E. coli Rosetta(DE3)pLysS culture (Fig. 2, lane 2) and in crude extracts of E. coli Rosetta(DE3)pLysS containing pET30TteAPC overnight culture in the presence of glucose, which strongly suppresses basal expression of proteins from the lac promoter. (Novy and Morris, 2001). Protein concentrations were estimated by the Bradford method for protein quantification (Bradford, 1976) using BSA as a standard (see Table I). The activity of recombinant Tte AP exonuclease was evaluated using fluorescein labeled dsDNA with inserted AP sites. Digested DNA was analyzed on agarose gel. To evaluate the activity of Tte AP exonuclease, control experiments were conducted with restriction enzyme ExoIII (Fermentas MBI, Lithuania). We obtained $45 \mathrm{mg}$ of pure His $_{6}$-tagged Tte AP exonuclease exhibiting $153 \mathrm{kU} / \mathrm{mg}$ specific activity from $500 \mathrm{ml}$ of cultured E. coli Rosetta(DE3)pLysS+ pET30TteAPC (Table I).

AP endonuclease, 3'-5' exonuclease and 3'-nuclease activities of Tte AP exonuclease. The evaluation of AP endonuclease activity of Tte AP exonuclease was performed using a synthetic DNA hybrid with two inserted AP sites (Fig. 3, Frame A). The DNA hybrid and products of the hybrid digestion were detected by fluorescein labeling the 5' end of the oligonucleotide. The products of digestion performed in buffers with different $\mathrm{Mg}^{2+}$ concentration were analyzed on highresolution NuSieve agarose (Fig. 3B). The effect of degradation is observed by change of mobility (band shift) of 5'-fluorescein labeled ssDNA or dsDNA due to DNA nicking or exonucleolytic degradation.

The Tte AP endonuclease activity is observed when $\mathrm{Mg}^{2+}$ concentration is below $1 \mathrm{mM}$, while 3' -5 ' exonuclease of the AP exonuclease activity is exhibited when $\mathrm{Mg}^{2+}$ concentration is $1.0 \mathrm{mM}$ or higher. The 

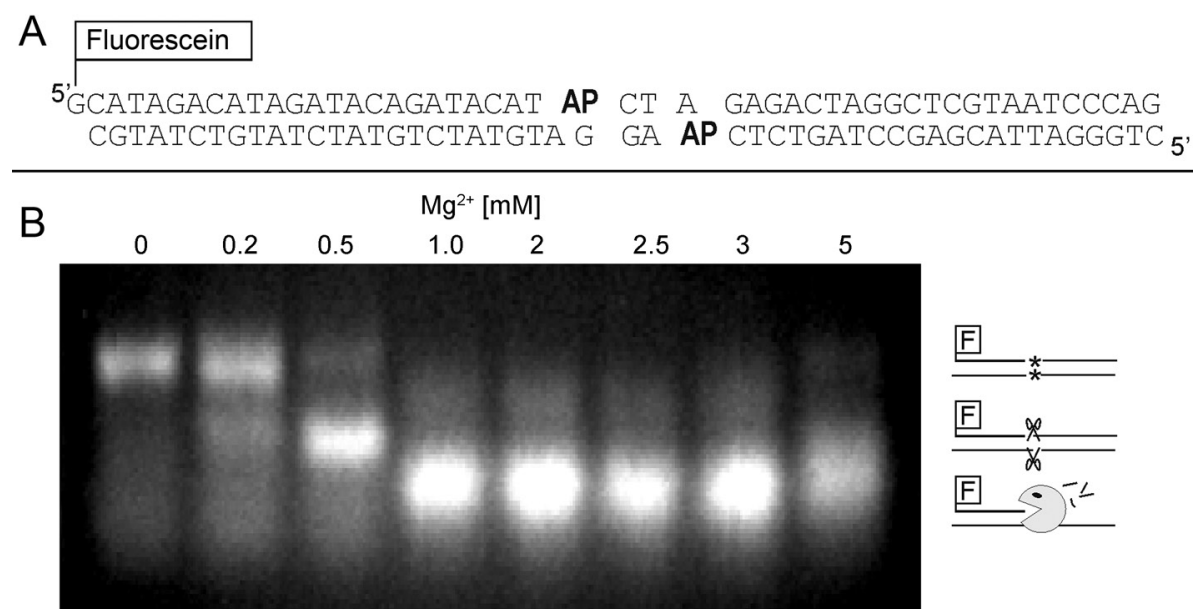

Fig. 3. AP endonuclease activity assay. (A) Structure of AP-DNA used in measurement of AP endonuclease activity. (B) The agarose gel electrophoresis analysis of products after digestion of 20 pmol of AP-DNA at indicated $\mathrm{Mg}^{2+}$ concentrations using $100 \mathrm{U}$ of Tte AP exonuclease.

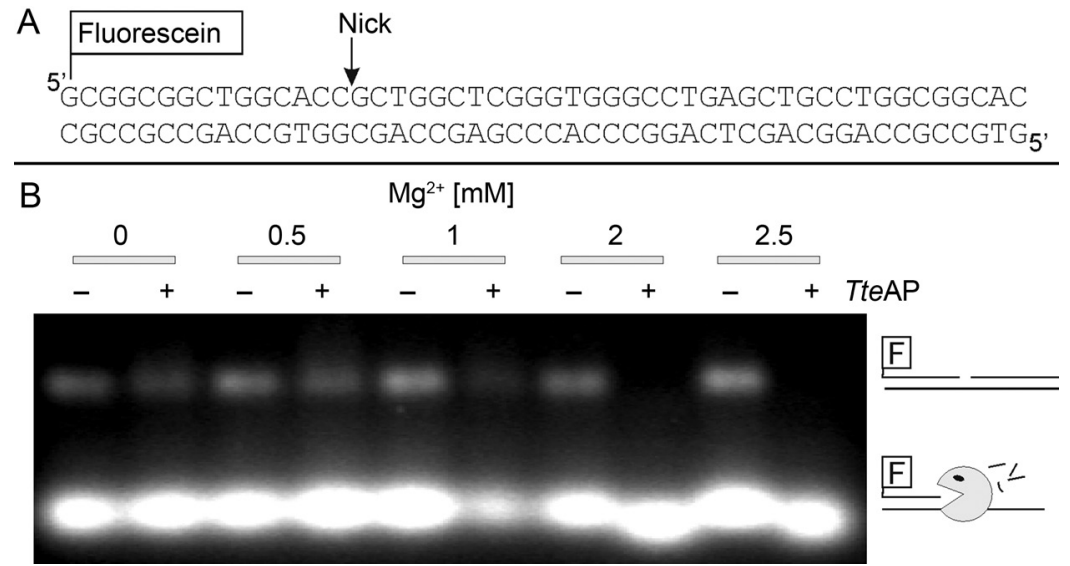

Fig. 4. 3'-5' exonuclease activity assay using nicked DNA. (A) Structure of hybrid DNA used in measurement of exonuclease activity. (B) The agarose gel electrophoresis analysis of products after digestion of $20 \mathrm{pmol}$ of hybrid DNA at indicated $\mathrm{Mg}^{2+}$ concentrations using $100 \mathrm{U}$ of Tte AP exonuclease (+) and without enzyme (-).
3'-5' exonuclease activity of Tte AP exonuclease was confirmed in assay with nicked DNA hybrid used as a substrate (Fig. 4A). The nicked DNA was incubated with and without Tte AP exonuclease in buffers with different $\mathrm{Mg}^{2+}$ concentration. The degradation of nicked DNA was exhibited when $\mathrm{Mg}^{2+}$ concentration reached $1.0 \mathrm{mM}$ (Fig. 4B). The 5'-3' exonuclease activity was also detected using fluorescein 5 ' labeled dsDNA with 5' cohesive end (Fig. 5A). The 3'-5'exonuclease activity was observed when $\mathrm{Mg}^{2+}$ concentration was over $1.0 \mathrm{mM}$ (Fig. 5B). The strong signal of small DNA fragment on Figure $4 \mathrm{~b}$ and $5 \mathrm{~b}$ is observed because of the overloading of fluorescein labeled primer (FluoroHyb1) during hybridization. This overloading was necessary to obtain stable DNA hybridization during enzymatic reaction at high temperature. Similar influence of various $\mathrm{Mg}^{2+}$ concentrations on exonucleolytic activities of E. coli ExoIII was also observed (Wilson et al., 1998). Therefore ExoIII is applied for many molecular biology techniques: degradation of 3' end for unidirectional mutagenesis (Henikoff, 1984), generation of a singlestranded template for DNA sequencing (Guo and Wu, 1982), site directional mutagenesis (Vandeyar et al., 1988), and many more.

Human Ape1 enzyme exhibits characteristic 3'-nuclease activity which is necessary in 3'mismatch repair

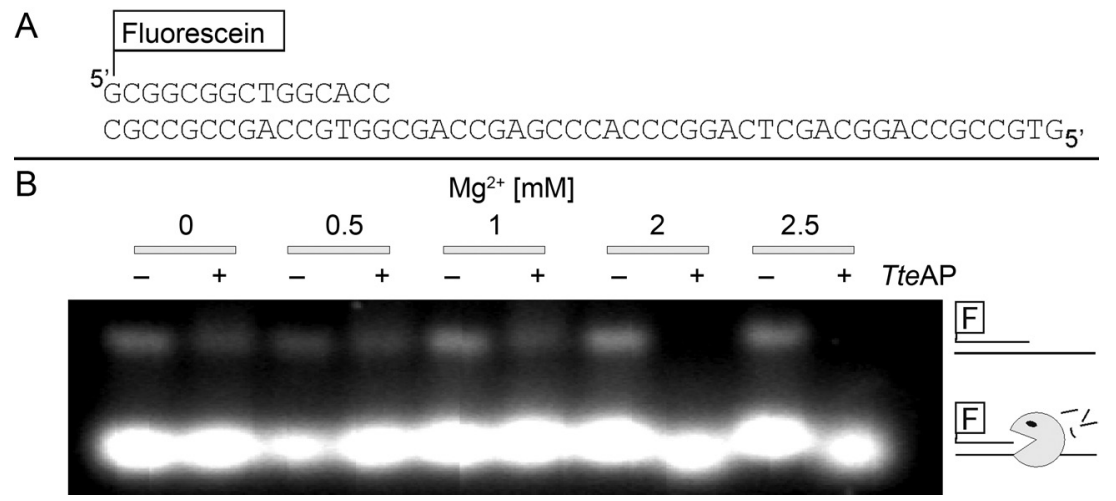

Fig. 5. 3'-5' exonuclease activity assay using DNA with 5' overhang. (A) Structure of hybrid DNA used in measurement of exonuclease activity. (B) The agarose gel electrophoresis analysis of products after digestion of 20 pmol of hybrid DNA at indicated $\mathrm{Mg}^{2+}$ concentrations using $100 \mathrm{U}$ of Tte AP exonuclease (+) and without enzyme (-). 

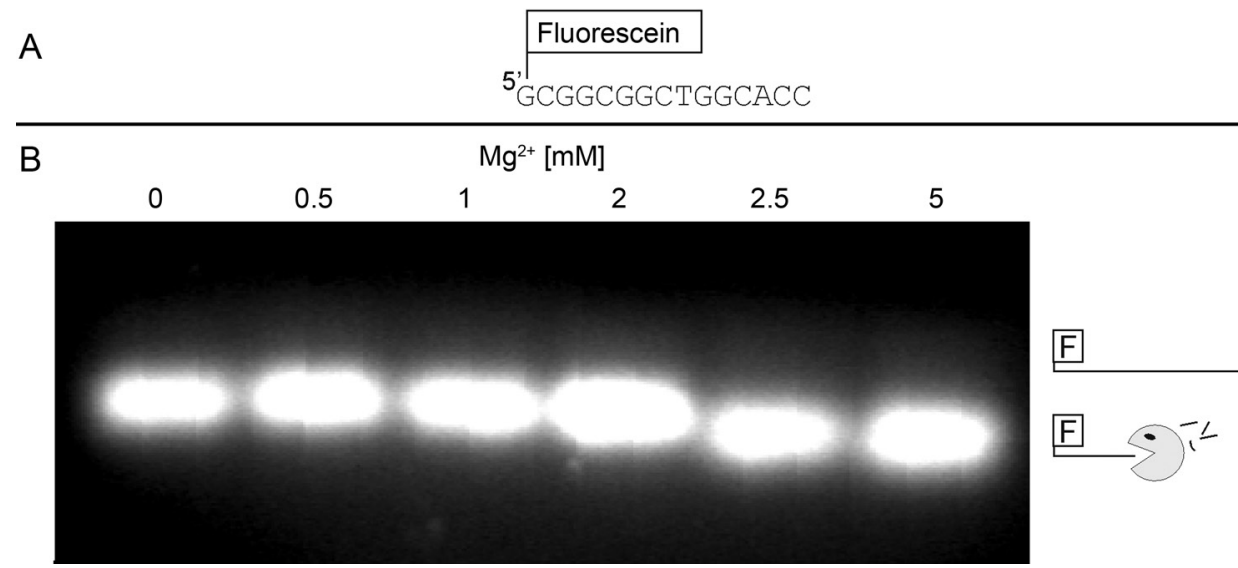

Fig. 6. 3'-nuclease activity assay. (A) Structure of ssDNA used in measurement of 3'-nuclease activity. (B) The agarose gel electrophoresis analysis of products after digestion of $20 \mathrm{pmol}$ of ssDNA at indicated $\mathrm{Mg}^{2+}$ concentrations using $100 \mathrm{U}$ of Tte AP exonuclease.

(Hadi et al., 2002), whereas this activity is absent in ExoIII enzyme. For the determination of 3'-nuclease activity from Tte AP exonuclease, the fluoresceinlabeled $15 \mathrm{nt}$ oligonucleotide was used (Fig. 6A). The oligonucleotide sequence was designed and examined using Vector NTI software and DNA secondary structure formation was not observed.

The oligonucleotide was incubated with the same amount of Tte AP exonuclease at different $\mathrm{Mg}^{2+}$ concentration at $70^{\circ} \mathrm{C}$ for $30 \mathrm{~min}$. The degradation of ssDNA was observed when $\mathrm{Mg}^{2+}$ concentration was over $2.0 \mathrm{mM}$ (Fig. 6B). The degradation of only a few nucleotides was observed due to fluorescein shielding of the 5 ' terminal binding sight of the enzyme. Function and endo- and exonuclease activities of Tte AP exonuclease are strongly depended on $\mathrm{Mg}^{2+}$ concentration. The presence of a 3'-nuclease activity domain in prokaryotic BER pathway systems is unique. A 3'-nuclease activity is a consequence of inherent high identity of the amino acid sequence, and most likely the structure similarity to human Ape1 exonuclease.

Thermostability of Tte AP exonuclease. The optimal temperature of growth of T. tengcongensis is $70^{\circ} \mathrm{C}$ at pH 7.0-8.0. Tte AP exonuclease should be very stable in these conditions because it is responsible for repairing AP sites, which are generated very frequently at high temperatures. For examination of Tte AP exonuclease thermostability, the synthetic fluorescein-labeled hybrid DNA (50 bp), with inserted AP sites, was used (Fig. 3A). $200 \mathrm{U}$ of enzyme were incubated at different temperatures with 10 pmoles of hybrid DNA for $15 \mathrm{~min}$ and analyzed on high-resolution NuSieve agarose gel
(Fig. 7). Inactivation of the enzyme was nearly complete at $84^{\circ} \mathrm{C}$ and above, and it is stable up to $80^{\circ} \mathrm{C}$. The activity of the enzyme was also observed at $37^{\circ} \mathrm{C}$, but that could be an effect of enzyme excess used in this assay.

Enhancing PCR amplification using Tte AP exonuclease. A number of modifications to the basic PCR method have been published in an attempt to increase the efficiency of amplification of long PCR products efficiency as well as the specificity of the reaction. The application of ExoIII protein of E. coli in long PCR reaction for elimination of AP sites has also been described (Fromenty et al., 2000).

Tte AP exonuclease was employed for elimination of AP sites generated in E. coli genomic DNA. The enzyme indicated strong 3'-5' exonuclease and 3'-nuclease activity at $2.5 \mathrm{mM} \mathrm{Mg}^{2+}$ (the $\mathrm{Mg}^{2+}$ amount usually applied in PCR reaction). Its AP endonuclease activity was exhibited at $0.5 \mathrm{mM} \mathrm{Mg}^{2+}$. Therefore, to avoid degradation of template DNA and primers, genomic DNA was treated with Tte AP exonuclease at the presence of $0.5 \mathrm{mM} \mathrm{Mg}^{2+}$. Then, the enzyme was inactivated at $90^{\circ} \mathrm{C}$ for $5 \mathrm{~min}$. PCR was performed with different amounts of genomic DNA and the products of reaction were analyzed on $1 \%$ agarose gel (Fig. 8). As previously described for ExoIII enzyme (Fromenty et al., 2000), improved PCR efficiency is observed because of elimination of AP-sites, and inhibition of DNA polymerase is not observed. The inhibition of PCR is mainly observed when high amount of genomic DNA was used (300, $100 \mathrm{ng}$ ) (Fig. 8, lanes 2 and 3), and at a lower level of DNA (10 ng) (Fig. 8, lane 5). The high PCR inhibition effect was observed at DNA damage levels below $3 \mathrm{ng}$

Fig 7. Thermostability of Tte AP exonuclease. The agarose gel electrophoresis analysis of 10 pmoles of AP-DNA incubated for $15 \mathrm{~min}$ with $200 \mathrm{U}$ of Tte

AP exonuclease at indicated temperatures.

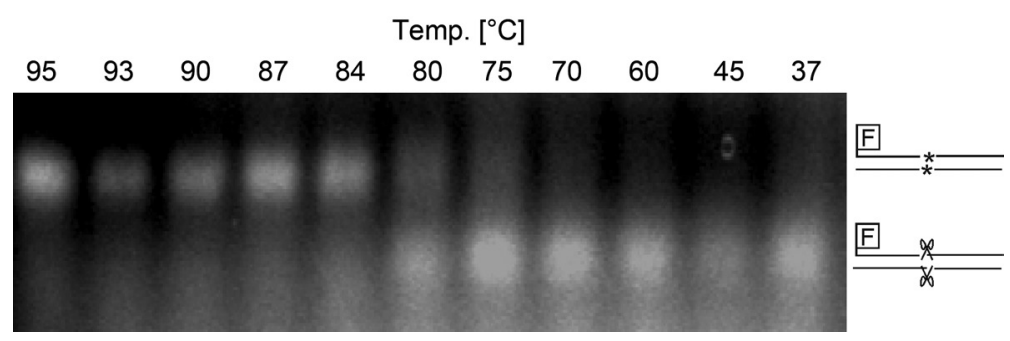




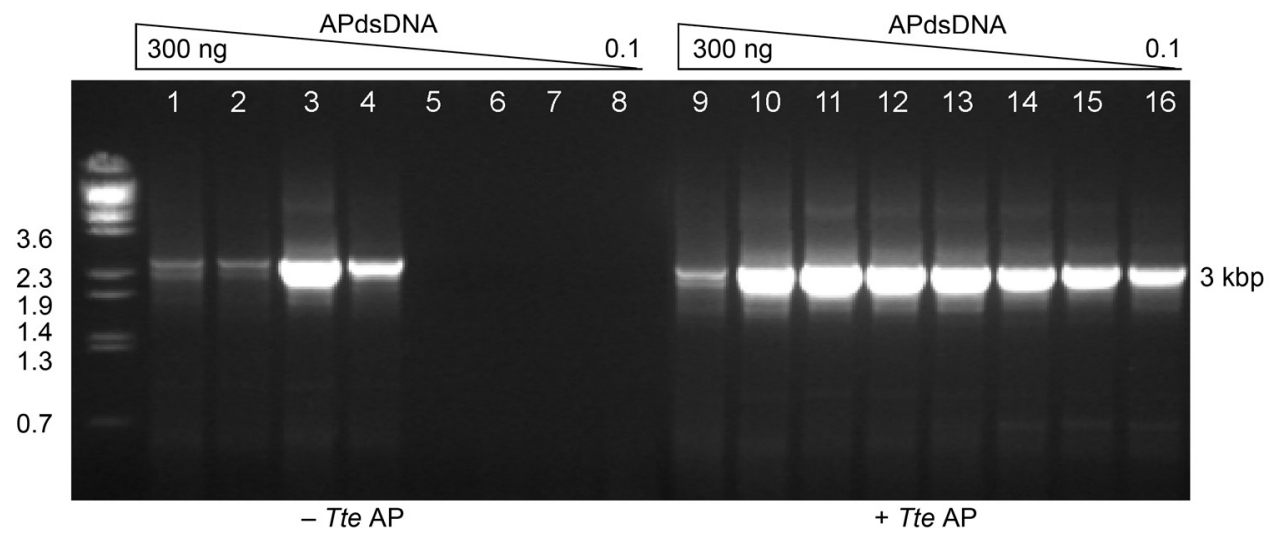

Fig. 8. Application of Tte AP exonuclease in PCR reaction. Analysis of PCR products after amplification using different amount of depurinated genomic DNA $300 \mathrm{ng}$ (lanes 1, 9), $100 \mathrm{ng}$ (lanes 2, 10), $33 \mathrm{ng}$ (lanes 3, 11), $10 \mathrm{ng}$ (lanes 4, 12), $3 \mathrm{ng}$ (lanes 5, 13), 1 ng (lanes 6, 14), $0.3 \mathrm{ng}$ (lanes 7, 15) and $0.1 \mathrm{ng}$ (lanes 8, 16) after $30 \mathrm{U}$ of Tte AP exonuclease pretreatment (+TteAP) for 15 min (lanes 9-16) and without enzyme treatment (-TteAP) (lanes 1-8).

(Fig. 8, lanes 6-9). The optimal amplification efficiency was obtained for $33 \mathrm{ng}$ of genomic DNA, where the ratio of AP sites of genomic DNA to amount of used for PCR DNA polymerase permits for the efficient PCR. The application of $30 \mathrm{U}$ Tte AP exonuclease eliminates AP sites before PCR (Fig. 8, lanes 11-16), but the ratio between number of AP sites and the amount of enzyme is still very high for repairing the highest concentration of genomic DNA (Fig. 8, lane 10).

The depurination effect of DNA is observed especially for samples stored for extended periods (historical samples) or/and stored in not optimal i.e. acidic conditions (Fromenty et al., 2000). Tte AP exonuclease could be a useful tool in amplification of DNA from this kind of samples.

\section{Literature}

Bao Q., Y. Tian, W. Li, Z Xu, Z. Xuan, S. Hu, W. Dong, J. Yang, Y. Chen, Y. Xue and others. 2002. A complete sequence of the T. tengcongensis genome. Genome Res. 12: 689-700.

Bennett R.A. 1999. The Saccharomyces cerevisiae ETH1 gene, an inducible homolog of exonuclease III that provides resistance to DNA-damaging agents and limits spontaneous mutagenesis. Mol. Cell. Biol. 19: 1800-1809.

Bradford M.M. 1976 A rapid and sensitive method for the quantitation of microgram quantities of protein utilizing the principle of protein-dye binding. Analyt. Biochem. 72: 248-254.

Brinkmann U., R.E. Mattes and P. Buckel. 1989. High-level expression of recombinant genes in Escherichia coli is dependent on the availability of the dnaY gene product. Gene 85: 109-114.

Carpenter E.P., Corbett A., Thomson H., Adacha J., Jensen K., Bergeron J., Kasampalidis I., Exley R., Winterbotham M., Tang C., Baldwin G.S., Freemont P. 2007. AP endonuclease paralogues with distinct activities in DNA repair and bacterial pathogenesis. The EMBO Journal 26: 1363-1372.

Chou K.M., M. Kukhanova and Y.C. Cheng. 2000. A novel action of human apurinic/apyrimidinic endonuclease: excision of L-configuration deoxyribonucleoside analogs from the 3' termini of DNA. J. Biol. Chem. 275: 31009-31015.
Dabrowski S. and B.K. Ahring. 2003. Cloning, expression, and purification of the His6-tagged hyper-thermostable dUTPase from Pyrococcus woesei in Escherichia coli: application in PCR. Protein Expr. Purif. 31: 72-78.

Dabrowski S. and J. Kur. 1998. Cloning and expression in Escherichia coli of the recombinant his-tagged DNA polymerases from Pyrococcus furiosus and Pyrococcus woesei. Protein Expr. Purif. 14: 131-138.

Demple B. and L. Harrison. 1994. Repair of oxidative damage to DNA: enzymology and biology. Annu. Rev. Biochem. 63: 915-948. Dubendorff J.W. and F.W. Studier. 1991. Controlling basal expression in an inducible $\mathrm{T} 7$ expression system by blocking the target $\mathrm{T} 7$ promoter with lac repressor. J. Mol. Biol. 219: 45-59.

Fromenty B., C. Demeilliers, A. Mansouri and D. Pessayre. 2000. Escherichia coli exonuclease III enhances long PCR amplification of damaged DNA templates. Nucleic. Acids. Res. 28: E50.

Guo L.H. and R. Wu. 1982. New rapid methods for DNA sequencing based in exonuclease III digestion followed by repair synthesis. Nucleic. Acids. Res. 10: 2065-2084.

Hadi M.Z., K. Ginalski, L.H. Nguyen and D.M. Wilson. 2002. Determinants in nuclease specificity of Ape1 and Ape2, human homologues of Escherichia coli exonuclease III. J. Mol. Biol. 316: 853-866.

Hadi M.Z. and D.M. Wilson. 2000. Second human protein with homology to the Escherichia coli abasic endonuclease exonuclease III. Environ. Mol. Mutagen. 36: 312-324.

Henikoff S. 1984. Unidirectional digestion with exonuclease III creates targeted breakpoints for DNA sequencing. Gene 28: 351-359. Johnson R.E., C. A. Torres-Ramos, T. Izumi, S. Mitra, S. Prakash and L. Prakash. 1998. Identification of APN2, the Saccharomyces cerevisiae homolog of the major human AP endonuclease HAP1, and its role in the repair of abasic sites. Genes Dev. 12: 3137-3143. Kneller D.G., F.E. Cohen. and R. Langridge. 1990. Improvements in protein secondary structure prediction by an enhanced neural network. J. Mol. Biol. 214: 171-182.

Lebedeva N.A., S.N. Khodyreva, A. Favre and O.I. Lavrik. 2003. AP endonuclease 1 has no biologically significant 3'-5'-exonuclease activity. Biochem. Biophys. Res. Commun. 300: 182-187.

McClelland J.L. and D.E. Rumelhart. 1988. Explorations in Parallel Distributed Processing. Vol.3. pp.316-362. MIT Press, Cambridge, MA.

Moffatt B.A. and P.K. Pfaffle. 1995. Single-step purification of a thermostable DNA polymerase expressed in Escherichia coli. Biotechniques 19: 780-784. 
Novy R., D. Drott, K. Yaeger and R. Mierendorf. 2001. Overcoming the codon bias of $E$. coli for enhanced protein expression. inNovations 12 : $1-3$.

Novy R. and B. Morris. 2001. Use of glucose to control basal expression in the pET System. inNovations 13: 8-10.

Porath J. and B. Olin. 1985. Affinity adsorption and immobilized metal ion chromatography of biomaterials. Serum protein affinities for gel-immobilized iron and nickel ions. Biochemistry 22: 1621-1630. Richardson C.C. and A.A. Kornberg. 1964. DNA phosphataseexonuclease from Escherichia coli. II. Characterization of the exonuclease activity. J. Biol. Chem. 239: 251-258.

Saitou N. and Nei M. 1987. The neighbor-joining method: a new method for reconstructing phylogenetic trees. Mol. Biol. Evol. 4: 406-425.

Schmiedel R., E.B. Kuettner, A. Keim, N. Sträter and T. GreinerStöffele. 2008. Structure and function of the abasic site specificity pocket of an AP endonuclease from Archaeoglobus fulgidus. DNA Repair (Amst). 8: 219-31.

Seidel H.M., D.L. Pompliano and J.R. Knowes. 1992. Phosphonate biosynthesis: molecular cloning of the gene for phosphoenolpyruvate mutase from Tetrahymena pyriformis and overexpression of the gene product in Escherichia coli. Biochemistry 31: 2598-2608.

Seki S., M. Hatsushika, S. Watanabe, K. Akiyama, K. Nagao and K. Tsutsui. 1992. cDNA cloning, sequencing, expression and possible domain structure of human APEX nuclease homologous to Escherichia coli exonuclease III. Biochim. Biophys. Acta 1131: 287-299.

Shida T., K. Kaneda, T. Ogawa and J. Sekiguchi. 1999. Abasic site recognition mechanism by the Escherichia coli exonuclease III. Nucleic. Acids. Symp. Ser. 42: 195-196.
Studier F.W. and B. A. Moffatt. 1986. Use of bacteriophage T7 RNA polymerase to direct selective high-level expression of cloned genes. J. Mol. Biol. 189: 113-130.

Suh D., D.M. Wilson and L.F. Povirk. 1997. 3'-phosphodiesterase activity of human apurinic/apyrimidinic endonuclease at DNA double-strand break ends. Nucleic. Acids. Res. 25: 2495-2500.

Unk I., L. Haracska, R.E. Johnson, S. Prakash and L. Prakash. 2000. Apurinic endonuclease activity of yeast Apn2 protein. J. Biol. Chem. 275: 22427-22434.

Unk I., L. Haracska, S. Prakash and L. Prakash. 2001. 3'-phosphodiesterase and 3' -5 ' exonuclease activities of yeast Apn2 protein and requirement of these activities for repair of oxidative DNA damage. Mol Cell Biol 21: 1656-1661.

Vandeyar M.A., M.P. Weiner, C.J. Hutton and C.A. Batt. 1988 A simple and rapid method for the selection of oligodeoxynucleotide-directed mutants. Gene 65: 129-133.

Wilson D.M. and D. Barsky. 2001. The major human abasic endonuclease: formation, consequences and repair of abasic lesions in DNA. Mutat. Res. 485: 283-307.

Wilson D.M., B. Engleward and L. Samson. 1998. Procariotic base excision repair. In DNA Damage and Repair pp. 29-64. Humana Press, Inc., Totowa, NJ.

Wilson D.M., M. Takeshita, A.P. Grollman and B. Demple. 1995 Incision activity of human apurinic endonuclease (Ape) at abasic site analogs in DNA. J. Biol. Chem. 270: 16002-16007.

Xue Y., Y. Xu, Y. Liu, Y. Ma and P. Zhou. 2001. Thermoanaerobacter tengcongensis sp. nov., a novel anaerobic, saccharolytic, thermophilic bacterium isolated from a hot spring in Tengcong, China. Int. J. Syst. Evol. Microbiol. 51: 1335-1341. 
